\title{
Life cycle assessment of resource recovery from municipal solid waste incineration bottom ash
}

\author{
Allegrini, Elisa; Vadenbo, Carl; Boldrin, Alessio; Astrup, Thomas Fruergaard
}

Published in:

Journal of Environmental Management

Link to article, DOI:

10.1016/j.jenvman.2014.11.032

Publication date:

2015

Document Version

Peer reviewed version

Link back to DTU Orbit

Citation (APA):

Allegrini, E., Vadenbo, C., Boldrin, A., \& Astrup, T. F. (2015). Life cycle assessment of resource recovery from municipal solid waste incineration bottom ash. Journal of Environmental Management, 151, 132-143.

https://doi.org/10.1016/j.jenvman.2014.11.032

\section{General rights}

Copyright and moral rights for the publications made accessible in the public portal are retained by the authors and/or other copyright owners and it is a condition of accessing publications that users recognise and abide by the legal requirements associated with these rights.

- Users may download and print one copy of any publication from the public portal for the purpose of private study or research.

- You may not further distribute the material or use it for any profit-making activity or commercial gain

- You may freely distribute the URL identifying the publication in the public portal

If you believe that this document breaches copyright please contact us providing details, and we will remove access to the work immediately and investigate your claim 
Accepted for publication in Journal of Environmental Management

\title{
Life cycle assessment of resource recovery from municipal solid waste incineration bottom ash
}

\author{
Allegrini, E. ${ }^{1}$, Vadenbo, C. $^{2}$, Boldrin, A. ${ }^{1}$, Astrup T.F. ${ }^{1}$ \\ ${ }^{1}$ Department of Environmental Engineering \\ Technical University of Denmark \\ Kgs. Lyngby, Denmark \\ ${ }^{2}$ Institute of Environmental Engineering \\ ETH Zurich \\ John-von-Neumann-Weg 9 \\ $\mathrm{CH}-8093$ Zurich, Switzerland
}

"NOTE: this is the author's version of a work that was accepted for publication in Journal of Environmental Management. Changes resulting from the publishing process, such as peer review, editing, corrections, structural formatting, and other quality control mechanisms may not be reflected in this document. Minor changes may have been made to this manuscript since it was accepted for publication. A definitive version is published in Journal of Environmental Management, vol 151, pp 132-143, doi: dx.doi.org/10.1016/j.jenvman.2014.11.032" 


\begin{abstract}
Bottom ash, the main solid output from municipal solid waste incineration (MSWI), has significant potential for the recovery of resources such as scrap metals and aggregates. The utilisation of these resources ideally enables natural resources to be saved. However, the quality of the recovered scrap metals may limit recycling potential, and the utilisation of aggregates may cause the release of toxic substances into the natural environment through leaching. A life cycle assessment (LCA) was applied to a full-scale MSWI bottom ash management and recovery system to identify environmental breakeven points beyond which the burdens of the recovery processes outweigh the environmental benefits from valorising metals and mineral aggregates. Experimental data for the quantity and quality of individual material fractions were used as a basis for LCA modelling. For the aggregates, three disposal routes were compared: landfilling, road sub-base and aggregate in concrete, while specific leaching data were used as the basis for evaluating toxic impacts. The recovery and recycling of aluminium, ferrous, stainless steel and copper scrap were considered, and the importance of aluminium scrap quality, choice of marginal energy technologies and substitution rates between primary and secondary aluminium, stainless steel and ferrous products, were assessed and discussed. The modelling resulted in burdens to toxic impacts associated with metal recycling and leaching from aggregates during utilisation, while large savings were obtained in terms of non-toxic impacts. However, by varying the substitution rate for aluminium recycling between 0.35 and 0.05 (on the basis of aluminium scrap and secondary aluminium alloy market value), it was found that the current recovery system might reach a breakeven point between the benefits of recycling and energy expended on sorting and upgrading the scrap.
\end{abstract}

Keywords: MSWI, Bottom ash, Scrap metal recovery, Aluminum recycling, LCA, Metals leaching

\title{
List of abbreviations
}

$\begin{array}{ll}\text { ADm } & \text { Depletion of abiotic mineral resource } \\ \text { Al scrap } & \text { Aluminium scrap } \\ \text { BA } & \text { Bottom ash } \\ \text { CF } & \text { Characterisation factor } \\ \text { ECS } & \text { Eddy current separator } \\ \text { ET } & \text { Ecotoxicity to freshwater } \\ \text { Fe } & \text { Ferrous metals } \\ \text { GWP } & \text { Global warming potential } \\ \text { HNFe } & \text { Heavy non-ferrous metals } \\ \text { HTC } & \text { Carcinogenic human toxicity } \\ \text { HTnc } & \text { Non-carcinogenic human toxicity } \\ \text { ISS } & \text { Inductive sorting system } \\ \text { LCA } & \text { Life cycle assessment } \\ \text { LCI } & \text { Life cycle inventory } \\ \text { LCIA } & \text { Life cycle impact assessment } \\ \text { L/S } & \text { Liquid to solid ratio } \\ \text { L/V } & \text { Liquid to volume ratio }\end{array}$


MSWI Municipal solid waste incineration

$\mathrm{NFe} \quad$ Non-ferrous metals

SS Stainless steel

TA Acidification

WtE Waste-to-Energy

XSS X-ray sorting system 


\section{Introduction}

The current waste management system in Europe generates approximately $35,000,000 \mathrm{Mg}$ of municipal solid waste incineration (MSWI) bottom ash (BA) annually (Eurostat, 2011). The management of this ash varies from country to country, though landfilling, the recovery of valuable metals, treatment and its utilisation as a construction material are among the possible options (Crillesen and Skaarup, 2006). However, increasing pressure on natural resources and concerns about possible losses of valuable resources in waste management have led to growing attention on waste flows such as MSWI BA, which bears potential from a resource perspective (Allegrini et al., 2014; Morf et al., 2013). Scrap metals can be recovered from BA, thereby avoiding mining and the production of primary metals, while the mineral fraction can be utilised within the construction industry, substituting natural aggregates and other natural materials.

Ferrous ( $\mathrm{Fe}$ ) and non-ferrous (NFe) scrap metals are found in MSWI BA in different grain size fractions (Allegrini et al., 2014; Biganzoli and Grosso, 2013; Hu and Rem, 2009; Hu et al., 2011b) and quality (Biganzoli and Grosso, 2013); in fact, scrap metals can be affected by loss of quality (e.g. due to oxidation, corrosion processes), which varies from metal to metal and between different grain sizes of the same metal type. The recovery of these metals at various levels is becoming common practice (Allegrini et al., 2014; Crillesen and Skaarup, 2006; Grosso et al., 2011; Heinrichs et al., 2012), and advanced recovery systems have been developed to reach high recovery efficiencies (De Vries et al., 2012; Muchová and Rem, 2006; ZAR, 2014). Enhanced metal recovery favours better utilisation of the mineral fraction in construction works and concrete production, for example by reducing swelling problems due to the oxidation of metallic aluminium residual content (Pecqueur et al., 2001). However, the low quality of scrap metals recovered after incineration affects the recycling phase and lowers the potential environmental benefits from recycling. Furthermore, the use of the mineral residues in more advanced applications could lead to increased demand for other materials (e.g. cement) to comply with structural requirements and potential release into the environment of toxic substances. Thus, a breakeven point, where benefits from resource recovery due to savings of natural resources outbalance the burdens of sorting, upgrading and utilising MSWI BA, might exist.

The comprehensive scope of assessment methodologies such as life cycle assessment (LCA) is suitable for identifying environmental benefits, problem shifting and breakeven points, and criticality related to the management of MSWI BA. Several studies have applied LCAs to analyse specific aspects of MSWI BA valorisation as a support for the implementation of new sorting systems or utilisation options (Barberio et al., 2010; Birgisdóttir et al., 2007; Boesch et al., 2014; Margallo et al., 2014; Meylan and Spoerri, 2014; Muchova, 2010; Toller et al., 2009) or to compare waste management systems where incineration and MSWI BA management are included (Georgeson, 2006; Kuusiola et al., 2012). However, so far, critical aspects such as the influence of recovered metal quality have not been addressed in LCA studies, and often impacts related to pollutants released into the environment during BA utilisation have been disregarded.

The objective of the present study was to assess the environmental impacts of an MSWI BA management system and identify critical aspects thereof, thus providing an improved basis for addressing the environmental assessment of waste-to-energy (WtE) systems. This was done by: i) collecting primary data at a full-scale MSWI BA recovery facility; ii) defining existing and alternative configurations of the plant with increasing metal recovery efficiencies; iii) characterising MSWI BA samples and concrete specimens with MSWI BA as aggregate, to estimate the potential release of pollutants into the environment; iv) evaluating toxic and non-toxic impacts 
of different recovery scenarios using LCA and v) identify critical parameters relating to resource quality and quantifying their impact on the environmental performance of the system.

\section{Material and Methods}

\subsection{The MSWI BA recovery system}

A Danish MSWI BA recovery system was used as a case study, a detailed description and analysis of the system is reported in Allegrini et al. (2014) and a simplified scheme of the system is reported in Fig. A.1. in the appendix. The system included the temporary storage of MSWI BA delivered from six MSWI plants, the recovery of Fe metals and upgrading before recycling, outdoor storage for ageing the BA to improve leaching behaviour, the recovery of NFe metals and upgrading of the scrap prior to recycling, the transportation of the mineral residue and metal scrap to utilisation/recycling sites and the utilisation of the treated BA as aggregate in a road subbase. The average composition of the BA treated in the system was determined in a previous study (i.e. Allegrini et al., 2014) and is summarised in Table 1.

Primary data were collected at the plant during measuring campaigns designed for this study. Electricity and diesel consumption for the sorting units at the recovery facility is reported in Table 2. The individual scrap metal types were transported to specific plants for secondary metal production, while the treated BA fraction was transported to road construction sites within Denmark to be used as aggregate in sub-bases. Data on transportation are reported in Table A.1. in Appendix A.

\subsection{LCA}

\subsubsection{Goal and scope definition}

The LCA was carried out following the guidelines reported in EC-JRC (2010). The goal of the LCA was to assess the environmental benefits and burdens of a MSWI BA recovery system with respect to the current treatment and disposal of MSWI BA and alternative configurations of the system in which higher metal recovery is expected to be achieved and alternative utilisation options for the treated BA are considered. The geographical scope was Denmark and the temporal scope for the future technology scenarios was within 10 years from the current situation. The time horizon for the life cycle inventory (LCI) analysis and impact assessment (LCIA) was 100 years (e.g. global warming potential at 100 years). The zero-burden assumption was applied, i.e. the burdens of MSWI BA generation were disregarded, and the FU was defined as "the treatment and management of one Mg of MSWI BA in Denmark". The LCA was carried out with the SimaPro v.8.0.2. LCA model (http://www.pre-sustainability.com/simapro) and an LCl of activities such as transportation, primary and secondary metal production, electricity production and diesel provision were retrieved from the Ecoinvent v.2.2 LCl database (http://www.ecoinvent.org/). System expansion, based on a consequential approach, was applied, and marginal technologies were therefore identified and used to account for multi-functionality (EC-JRC, 2010; Weidema et al., 1999).

\subsubsection{Scenarios}

Figure 1 schematically presents activities included within the system boundaries, while Table 3 summarises the ten scenarios included in this study. Detailed information about energy consumption in each scenario is reported in Table A.2. in Appendix A. 
The same recovery of Fe scrap was assumed for all scenarios (except for scenario $\mathrm{K}$ ), while the recovery efficiency of NFe scrap was varied from $0 \%$ up to a hypothetical efficiency equal or larger than $95 \%$. Scenario A was the reference scenario in which NFe scrap was not recovered and the mineral fraction was disposed of in a landfill site.

Table 1 - Composition of MSWI BA delivered to the recovery system and recovery efficiencies for a Danish state-ofthe-art system (based on Allegrini et al., 2014).

\begin{tabular}{lcc}
\hline Material fraction & $\begin{array}{c}\text { Content on } \\
\text { a wet basis } \\
\%\end{array}$ & $\begin{array}{c}\text { Recovery } \\
\text { efficiency } \\
\%\end{array}$ \\
\hline Mineral fraction (with average moisture content of 12\%) & 90 & \\
\hline Combustible materials & 0.11 & 85 \\
\hline Ferrous scrap (Fe) & 7.2 & 61 \\
\hline Non-Ferrous scrap (NFe) & 2.2 & 62 \\
Aluminium scrap (Al scrap) & 1.4 & 43 \\
Heavy NFe (HNFe) scrap (Cu, Pb, Zn etc.) & 0.49 & 85 \\
\hline Stainless Steel (SS) & 0.29 & \\
\hline Total & 100 & \\
\hline
\end{tabular}

Table 2 - Electricity and fuel demand for metal sorting and upgrading activities. Data are reported together with the respective values for relative standard deviation.

\begin{tabular}{|c|c|c|c|}
\hline Plant unit & Main machineries & $\begin{array}{l}\text { Electricity consumption } \\
\text { per } \mathrm{Mg} \text { of material } \\
\text { treated at the unit }\end{array}$ & $\begin{array}{l}\text { Diesel consumption per } \mathrm{Mg} \text { of } \\
\text { material treated at the unit }\end{array}$ \\
\hline Fe recovery unit & $\begin{array}{l}50 \mathrm{~mm} \text { drum screen; two } \\
\text { magnetic separators; conveyor } \\
\text { belts and a frontloader loading } \\
\text { the system }\end{array}$ & $0.24 \mathrm{kWh} / \mathrm{Mg} \mathrm{BA} \pm 48 \%^{\mathrm{a}}$ & $0.3 \mathrm{l} / \mathrm{Mg} \mathrm{BA} \pm 23 \%^{\mathrm{b}}$ \\
\hline Fe upgrading unit & $\begin{array}{l}\text { Rotating drum; } 10 \mathrm{~mm} \text { drum } \\
\text { screen; two magnetic separators; } \\
\text { conveyor belts and a frontloader } \\
\text { loading the system }\end{array}$ & - & $2.1 \mathrm{l} / \mathrm{Mg}$ Fe scrap $\pm 47 \%^{\mathrm{c}}$ \\
\hline NFe recovery unit & $\begin{array}{l}\text { Three sieves; three eddy current } \\
\text { separators (ECS); one inductive } \\
\text { sorting system (ISS); conveyor } \\
\text { belts and a frontloader loading } \\
\text { the system }\end{array}$ & - & $\begin{array}{l}0.51 \mathrm{l} / \mathrm{Mg} \text { pre-treated } \mathrm{BA} \pm \\
17 \%^{\mathrm{d}}\end{array}$ \\
\hline NFe upgrading unit & $\begin{array}{l}\text { Industrial system, including a } \\
\text { complex system of sieves, ECS, } \\
\text { ISS, X-ray sorting systems (XSS) } \\
\text { and sorting tables }\end{array}$ & 58 kWh/Mg NFe scrap & $0.83 \mathrm{l} / \mathrm{Mg}$ NFe scrap ${ }^{\mathrm{e}}$ \\
\hline \multicolumn{4}{|c|}{$\begin{array}{l}\text { Uncertainty estimate based on measurements at the plants over a one-year period. The number of measurements } \\
\text { varied: } \\
{ }^{a} 4 ;{ }^{b} 7{ }^{c} 8 ;{ }^{d} 3 \text {; and }{ }^{e} \text { only one value available. }\end{array}$} \\
\hline
\end{tabular}




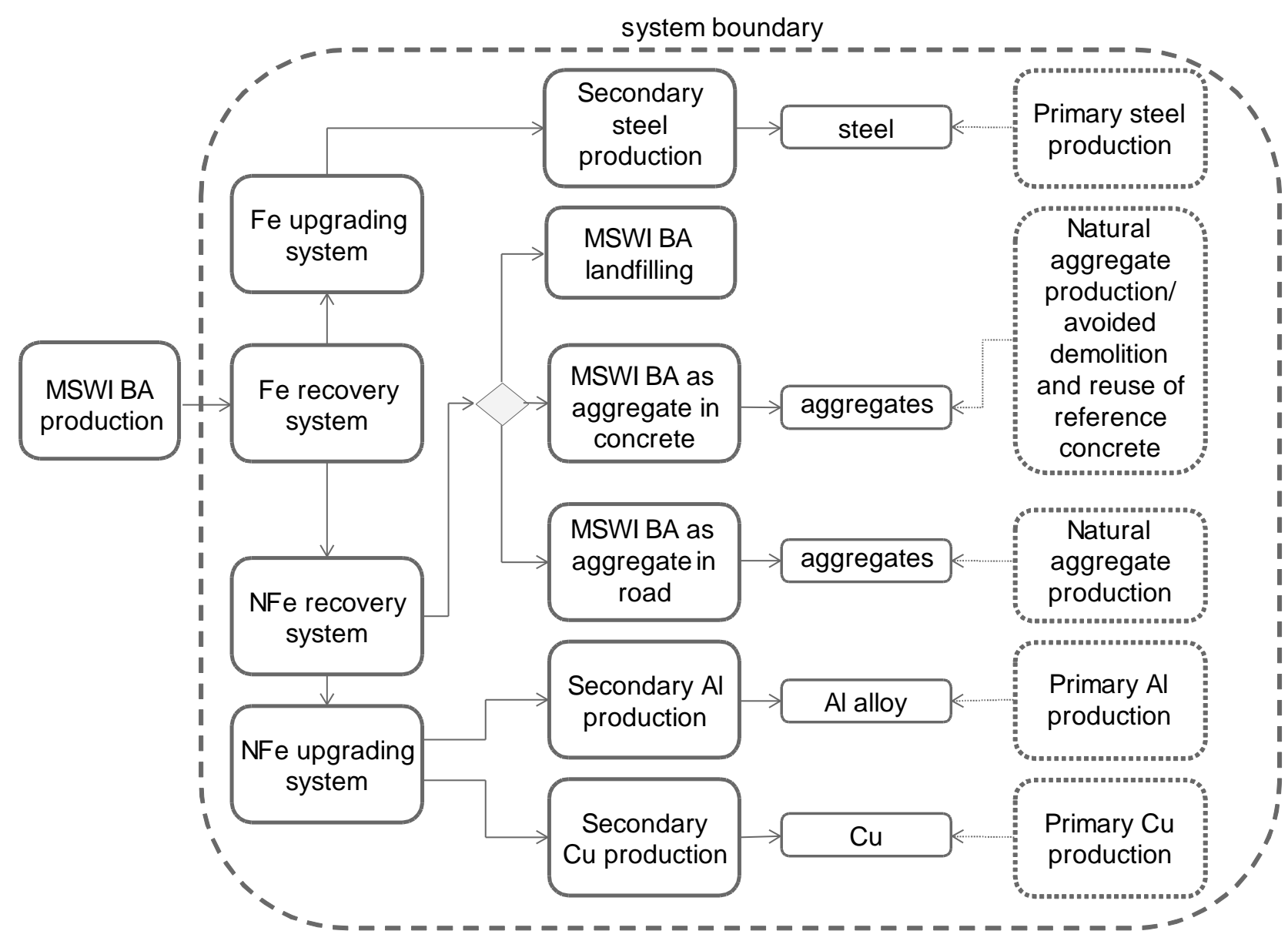

Figure 1 - System boundary overview.

For scenarios D, E and F, MSWI BA is used as aggregate in concrete and three types of concrete specimen (type 1, 2 and 3) were produced and provided by the Danish Technological Institute (DTI). For all types of concrete, both specimens with natural aggregate and those with $100 \%$ substitution of the natural aggregate with MSWI BA were provided. Types 1 and 2 were two variants of plastic concrete with MSWI BA aggregates below $16 \mathrm{~mm}$ and requiring additional cement with respect to the reference formulation, namely 0.051 and $0.027 \mathrm{~kg}$ cement $\cdot \mathrm{kg}^{-1} \mathrm{BA}$, respectively. Type 3 was a dry concrete with MSWI BA aggregate below $8 \mathrm{~mm}$ substituting for sand filler. In this recipe no additional cement was used in the concrete formulation. All three concrete specimens were formulated with BA substituting $100 \%$ for sand. Only fine fractions of BA were used for a worst case scenario in terms of the potential release of contaminants from the concrete block and the increased demand for cement to comply with structural requirements. The utilisation of BA in concrete is currently not practiced in Denmark, while it is carried out in other European countries where BA can be used in concrete with limitations on its applications and the percentage of substituted natural aggregates (Van der Wegen et al., 2013). 
Table 3 - Overview of the ten scenarios included in the LCA.

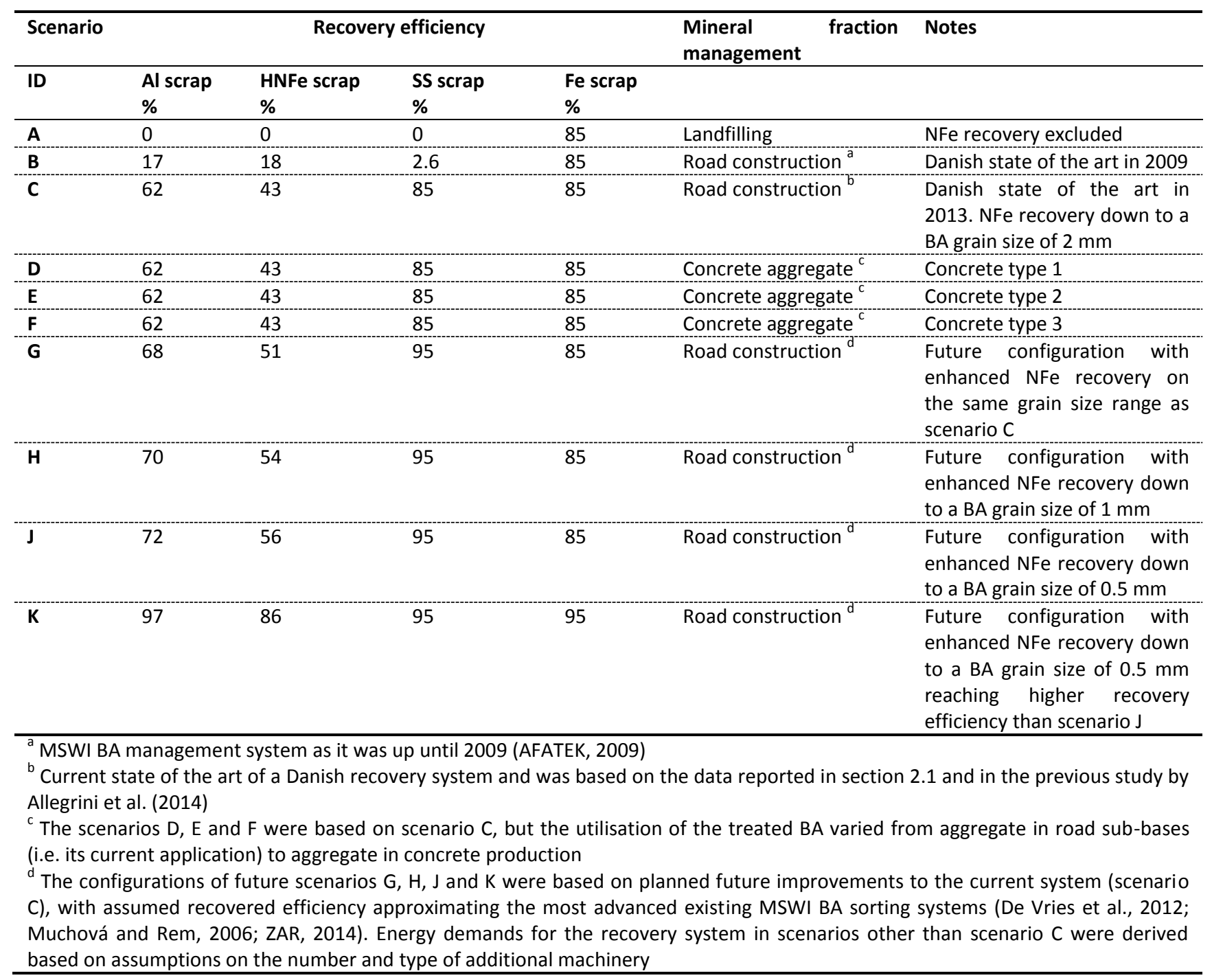

\subsubsection{Release of toxic substances during MSWI BA utilisation}

Experimental leaching tests were carried out to determine the potential release of inorganic pollutants into the natural environment in scenarios $D, E$ and $F$ where MSWI BA is utilised in concrete. While, literature data from Astrup at al. (2010) were elaborated to estimate pollutants release during 100-year MSWI BA landfilling or utilisation in road sub-bases. Details on experimental procedures and leaching estimates are provided in Appendix $B$.

In scenarios $D, E$ and $F$, the concrete specimens were assumed to be used for 50 years as part of outdoor pavements in the form of $0.3 \times 0.3 \times 0.05 \mathrm{~m}$ tiles, then dismantled (removed, crushed and mildly aged in outdoor piles, as commonly done for construction and demolition waste) and reused as aggregate in road construction for another 50 years. Concrete specimens of types 1, 2 and 3 (containing MSWI BA and reference specimens) were subjected to tank leaching tests following the NEN 7375 (2005) procedure and to the availability leaching test NEN 7371 (2004) . The results of these two leaching tests were used to calculate the diffusion coefficients of pollutants, to estimate their release from the concrete tiles during the 50 -year period in the model reported by Kosson et al. (1996) and Birgisdóttir (2005) (cf. Appendix B). In order to simulate the 
demolition phase and release during the 50 years of subsequent utilisation in a road sub-base, one specimen of each type was crushed with a jaw crusher down to $4 \mathrm{~mm}$ and aged in the laboratory. For the ageing procedure, the material was spread in a thin layer (approximately $0.5 \mathrm{~cm}$ ), turned over and mixed with distilled water twice a week until $\mathrm{pH}$-stable conditions were reached (approximately six weeks). The aged material underwent a compliance leaching test EN 12457-1 (2002) carried out at a liquid-to-solid ratio (L/S) of $2 \mathrm{l} / \mathrm{kg}$, as required by the Danish statutory order for the utilisation of residual materials in road construction (N. 1662: 2010). Contact between water and the material in the utilisation scenario was modelled using the approach provided by Kosson et al. (1996) and Birgisdóttir (2005) and described in Appendix B. The estimated median $\mathrm{L} / \mathrm{S}$ was $2.4 \mathrm{l} \cdot \mathrm{kg}^{-1}$ after 50 years utilisation in road, and release data from the leaching test EN 12457-1 (2002) were directly applied. Using the same approach, the median L/S ratios reached after 100 years landfilling or utilisation in road of MSWI BA were 1.6 and $4.9 \mathrm{I} \cdot \mathrm{kg}^{-1}$, respectively, and leaching data from column leaching test experiments prEN 14405 (2014), published by Astrup et al. (2010), were used. Emissions of metals from the disposal/utilisation scenarios were assumed emitted entirely to soil.

As different grain size fractions of MSWI BA were utilised in the concrete production process, the EN 12457-1 (2002) leaching test was performed on BA samples with specific grain sizes. Three samples of BA output from the treatment system (i.e. treated BA) were collected at the facility. Part of the collected samples was mass reduced and directly analysed, while the other part was screened in large plastic sieves to obtain the BA fractions $16-50 \mathrm{~mm}, 8-16 \mathrm{~mm}, 2-8 \mathrm{~mm}$ and below $2 \mathrm{~mm}$.

Emissions of metals through leaching were estimated exclusively over a 100-year time horizon, following common practice within the LCA. However, while it is well-recognised that the release of metals from ashes may potentially continue over many thousands of years (e.g. Astrup et al., 2006; Doka and Hischier, 2005), no consensus methodology has yet been found (Laner, 2009). Thus, in this study, long-term emissions (beyond the initial 100-year period) were excluded and the focus was placed on assessing the more immediate environmental consequences.

\subsubsection{Scrap metal recycling}

Four types of scrap metals were considered for secondary metal production: aluminium (Al) scrap, heavy non-ferrous (HNFe) scrap, stainless steel (SS) scrap and ferrous (Fe) scrap. Information about scrap quality was scarce for Al and HNFe and unavailable for SS and Fe, so assumptions based on available information in the literature were used to define recycling processes and substitution paths. In all scenarios, processes for secondary production and the avoided production of displaced products were retrieved from the Ecoinvent v.2.2 database, and the utilised Ecoinvent processes are listed in Table A.3. in Appendix A.

\subsubsection{Stainless steel (SS), ferrous (Fe), and Heavy non-ferrous (HNFe) scrap}

Information about the quality and fate of SS and Fe scrap was not available. The recycling was modelled with an assumed yield in the secondary production phase of $90 \%$. Complete substitution was assumed (i.e. that $1 \mathrm{~kg}$ of secondary steel displaced $1 \mathrm{~kg}$ of primary steel); however, downcycling of the recycled SS and Fe scrap, due to contamination and the accumulation of alloying elements, may lead to lower actual substitution rates between the primary and the secondary product (cf. Nakajima et al., 2011). The HNFe fraction contained a mixture of metals (e.g. $\mathrm{Cu}$, brass, $\mathrm{Ni}, \mathrm{Pb}, \mathrm{Zn}$ and precious) whose relative content was estimated based on Allegrini et al. (2014) and personal communications with the NFe upgrading facility. HNFe were divided at the 
upgrading facility into the fractions $>10 \mathrm{~mm}, 10-5 \mathrm{~mm}$ and 5-2 $\mathrm{mm}$ and additionally $2-1 \mathrm{~mm}$ and $<1$ $\mathrm{mm}$ for recovery in future process configurations. The coarse fraction was exported to China, where different metals were manually sorted and recycled more economically than could possibly be done in Europe, and $20 \%$ of this fraction was assumed to be recovered as copper. The other fractions (below $10 \mathrm{~mm}$ ) were sent as bulk to copper smelters in Europe. In the secondary copper smelter, the HNFe fraction is fed into the furnace to produce black copper, which is used for anode casting for subsequent electrorefining. During electrorefining pure $\mathrm{Cu}$ accumulates at the cathode, $\mathrm{Ni}$ is recovered through electrolyte purification as $\mathrm{NiSO}_{4}$, and other metals (i.e. precious metals) are enriched in the anode slime, which is then treated for further recovery. Impurities such as Fe, $\mathrm{Pb}, \mathrm{Sn}$ and $\mathrm{Zn}$ are easily lost in the off-gas and through oxidation (Schlesinger et al., 2011). Cu yield for the HNFe fraction after the entire process was approximately $60 \%$ for scrap of grain size between 10 and $5 \mathrm{~mm}$, and $76 \%$ in the fraction below $5 \mathrm{~mm}$. The substitution rate between primary and secondary copper production was assumed to be 1 . Because of a lack of data for the recycling of other metals in the HNFe scrap (i.e. precious metals), only copper recycling was included.

\subsubsection{Aluminium (Al) scrap}

Al scrap was also divided according to the abovementioned grain size fractions at the upgrading facility, and all Al fractions were treated at refiners within Europe. Because of the substantial amount of energy required for primary Al production, there is economic and environmental interest in recovering this metal. However, Al scrap quality is a critical factor that may significantly affect the environmental benefits associated with recycling. The quality of Al scrap is compromised by oxidation (Biganzoli and Grosso, 2013), contamination and the inherent content of alloying elements (Nakajima et al., 2010). In particular, the inherent content of alloying elements in the scrap determines the potential utilisation of the secondary product and the need to add primary aluminium or high-grade aluminium alloy scrap to obtain the desired cast alloy quality. Old Al scrap (post-consumer and post-incineration scrap) includes a mixture of aluminium alloys that is treated by refiners for producing cast alloy, and deoxidation aluminium which is used in the steel industry. In principle, old Al scrap cannot be used by re-melters to produce wrought alloys (a major product of the primary aluminium industry), whose content of alloying elements may not exceed $10 \%$. Thus, there is an inherent change of properties between primary and secondary aluminium products, and material downcycling occurs in the case of metal scrap recycling. Based on literature information about Al scrap oxidation (Biganzoli et al., 2013), and on personal communication with the secondary aluminium sector, aluminium yields from individual scrap fractions were estimated at $81 \%, 72 \%, 66 \%$ and $12 \%$, respectively, for the fractions $>10 \mathrm{~mm}$, 10-5 mm, 5-2 $\mathrm{mm}$ and $<2 \mathrm{~mm}$. The substitution rate between secondary and primary aluminium was assumed to be 1 in the baseline scenario.

\subsubsection{Marginal technologies}

Following the consequential approach to system expansion, marginal technologies were used. The approach of Weidema et al. (1999) was applied for identifying technologies/materials actually affected by marginal changes in the system as a result of MSWI BA recovery system. This was particularly relevant for metal recycling and electricity provision, which were shown in previous studies as having a significant influence on the final result (e.g. Fruergaard et al., 2009; Schmidt and Thrane, 2009; Sevigné-Itoiz et al., 2014). Concerning metal recycling, a global perspective was used. While secondary production was assumed to occur within Europe, primary production was 
considered at a global level. For all four metal types, marginal primary productions were assumed to take place in China - a choice which was based on the significant growth in production in China in the last decade (EAA, 2013b; IAI, 2013; ICSG, 2013; ISSF, 2013; World steel association, 2013). This means that, within the present study, a change in demand caused by a marginal change of production of secondary metals in Europe was covered by a marginal change in production in relation to the primary metal in China. A main implication of such a modelling approach is that the two regions can have different marginal technologies for electricity production, whereby electricity consumption plays a significant role, as metal refining processes are highly energyintensive. The marginal technology for electricity production in Europe was based on hard coal, as previously identified by Fruergaard (2010). Hard coal was also identified as marginal for Chinese electricity production, based on data reported by IEA (2008). Thus, the fuel used in the marginal technology for energy provision was the same in the two cases, but the impacts differed due to differences in technology level, efficiency of the power plants and levels of environmental regulations at a regional level.

\subsubsection{Sensitivity analysis of aluminium recycling}

To reflect the importance of aluminium recovery and recycling for the environmental performance of MSWI BA management, specific attention was given to assumptions and the modelling of aluminium recycling. Sensitivity analysis was performed on key parameters, including marginal electricity and production technologies as well as substitution rates.

\subsubsection{Marginal technology}

Three scenario analyses were performed by varying the marginal technology for primary aluminium production:

As recommended by Schmidt and Thrane (2009), a mix of technologies was used for marginal primary aluminium production (i.e. 60\% China, 22\% Russia and 18\% Middle East) and electricity production (i.e. $62 \%$ coal, $9 \%$ gas and $29 \%$ hydropower).

The production capacity for primary aluminium in the Middle East (i.e. in countries within the Gulf Cooperation Council) has been increasing significantly since 2010, and it is expected to grow further due to the region's oil and gas reserves. Hence, $100 \%$ production in the Middle East, based on $100 \%$ natural gas, was set as a marginal electricity source (IAI, 2013; IEA, 2008) in the second scenario analysis.

Most old Al scrap is used to produce the alloy EN AB-46000 (according to the standard EN 1676 (1997)), which is mainly used by the car industry (Modaresi and Müller, 2012). Whereas global car production has continued to grow in the past decade, driven primarily by an increase in demand by the Chinese market, the production of cars in Europe has shown signs of stagnation in recent years (ACEA, 2010; ICCT, 2013; OICA, 2014). From a regional perspective, decreasing car production volumes in Europe may be expected to result in the least competitive material option being affected when additional Al scrap is recycled. For this scenario, we assume that automotive components manufactured from conventional cast iron are displaced. At a global level, the car industry is growing, and so a change in demand or the availability of a material in the car industry affects the marginal source of additional material for the relevant components, which are here assumed to be represented by primary aluminium. Both of these fundamentally different outlined situations will therefore be included in the sensitivity analysis. 


\subsubsection{Substitution rate}

A scenario analysis was performed by varying the substitution rate between secondary and primary aluminium. A range of substitution rates was defined based on the value-corrected substitution method, as recommended by the European Aluminium Association (EAA, 2013a), and its modifications, as described in Koffler and Florin (2013). The substitution rate for secondary aluminium alloys was indicated by the Greek letter $\beta$, and it was defined as:

The ratio between the London Metal Exchange (LME) quotation for secondary alloys and primary aluminium (Al 99.7) following the EAA method. In this case, using the aluminium alloy price from the LME, $\beta$ was set at 0.9 (Koffler and Florin, 2013), and by applying prices for the secondary aluminium EN AB-46000, this ratio was found to be approximately 0.05. Additionally, a differentiation between the qualities of Al scrap in different grain size fractions was made, as quality is related to the grain size of scrap, and different oxidation levels and alloying element content were found. For example, a fine fraction (i.e. below $5 \mathrm{~mm}$ ), even though highly oxidised, is purer in terms of aluminium content. As observed in recent studies (Biganzoli et al., 2012; Hu et al., 2011a), Al scrap partitioning in MSWI BA depends mainly on feedstock going into the incineration process: aluminium from foils, made of alloy with aluminium content above $98 \%$ (ASTM B479, 2006), tends to enrich in the fine fractions of MSWI BA. Thus, the fine fraction of the Al scrap could be used by re-melters for wrought alloy production instead of being used for the production of cast alloys. For sensitivity, $\beta=1$ was assigned to the fine fraction and $\beta=0.35$ to the coarse Al scrap.

The ratio between scrap prices (instead of secondary aluminium prices) and primary aluminium was proposed by Koffler and Florin (2013) in order to show the level of downcycling reached after a product's lifecycle comes to an end. However, for the sake of consistency within the study, the system boundaries were here not modified according to the approach proposed by Koffler and Florin (2013), so the production of secondary aluminium was always included. On the basis of the list of scrap class reported by the same authors, possible $\beta$ for post-incineration scrap was below 0.35 , which is the substitution ratio found by the authors for old mixed scrap aluminium.

Additionally, two combined sensitivity analyses were performed to include the effect of the quality of the Fe and SS scrap and the energy demand of the sorting and upgrading system for the scrap. At first the substitution ratio for SS and Fe scrap (indicated as $\alpha$ and $\gamma$, respectively) varied between 0 and 1 at a given value of $\beta$. Subsequently the substitution rate for SS was set to 1 and $\beta$, $\gamma$, and the impacts of the sorting and upgrading system were varied simultaneously, in order to locate possible environmental breakeven points.

\subsubsection{Impact assessment}

Inventoried emissions were characterised in the LCIA. Both toxic and non-toxic impact categories were included: global warming potential (GWP) based on IPCC 2007 over a 100-year time horizon; acidification (TA) (Posch et al., 2008; Seppälä et al., 2006); mineral abiotic resource depletion (ADm) based on CML v.4.2 (Van Oers et al., 2002); carcinogenic human toxicity (HTc), noncarcinogenic human toxicity (HTnc) and ecotoxicity to freshwater (ET) based on the USEtox model (Rosenbaum et al., 2008). The LCIA methodologies were selected according to the recommendations provided by Hauschild et al. (2013). 


\section{Results and discussion}

\subsection{Non-toxic potential impacts}

\subsubsection{Potential impacts on the global warming potential (GWP) category}

Figure 2 presents the results of the LCA analysis for the non-toxic categories. The MSWI BA recovery system resulted in increasing benefits (negative impacts) for GWP proportionally to metal recovery, due to large savings obtained from recycling Al scrap (more than $50 \%$ of the total net impact). Owing to the large difference in energy demand between primary and secondary aluminium production, benefits also resulted from the recycling of the highly oxidised Al scrap fractions. However, the drawbacks of using low-quality Al scrap in refining processes (i.e. increased production of slag to be disposed/treated/recovered) were not included because of a lack of quantitative data, indicating that actual benefits could be somewhat smaller. Recycling of Fe scrap also resulted in significant savings, accounting for approximately $35 \%$ of the total impacts in the baseline scenario (C). Copper and SS recycling contributed less than $5 \%$ because of the smaller amounts recovered, while sorting activities and transportation contributed approximately $1 \%$ and $2 \%$, respectively, of the total potential impacts. Based on data collected at the sorting plant, the basic scenario required approximately $11 \mathrm{kWh}$ per $\mathrm{Mg}$ of treated $\mathrm{BA}$; however, doubling the electricity demand of the system up to a level similar to other facilities (e.g. $20 \mathrm{kWh} / \mathrm{Mg} \mathrm{BA}$ in ZAR (2014)), the contribution of the sorting activity remained below 5\% (result not shown). Also, increasing transportation distances by $10 \%$ did not affect the results. Disposing of the treated BA through landfilling or using $B A$ in road construction showed negligible potential impacts. The use of MSWI BA as aggregate in concrete, substituting $100 \%$ of natural aggregates, however, resulted in increased demand for cement compared to the reference product without BA, thereby contributing significantly to the GWP category and representing up to $13 \%$ of the total net impact in scenario $D$.

\subsubsection{Sensitivity analysis for the GWP impact category}

The calculated savings in Figure 2 were based on the most favourable recycling situation: the use of Chinese production as marginal and a substitution rate between primary and secondary products equal to 1 . However the GWP score is influenced largely by the choice of marginal technology. When changing the marginal source of electricity in primary aluminium production from $100 \%$ coal in China to a composite marginal mix reflecting aluminium production in China, Russia and the Middle East (Schmidt and Thrane, 2009), and to a marginal reflecting $100 \%$ production in the Middle East (100\% natural gas), savings for the entire system (in scenario C) were reduced by $16 \%$ and $26 \%$, respectively. Savings dropped by $57 \%$ when Al scrap recycling was assumed to displace the production of cast iron. Similarly, by varying the substitution rate (cf. section 2.2.5), savings across the entire system decreased from $6 \%(\beta=0.9)$ to $58 \%(\beta=0.05)$ with respect to the base scenario. Additional substitution ratios were also tested down to $\beta=0$, and the breakeven point (i.e. the point of balance between environmental savings and burdens) for the sole aluminium recycling activity was reached at a substitution value of approximately 0.04 for scenario C. By differentiating the substitution rate between fine and coarse Al scrap, a 16\% saving reduction was made with respect to the base scenario (i.e. $\beta=1$ for all Al scrap recycled). The above mentioned results are reported in Fig. C.1. and Fig.C.2. in Appendix C. 

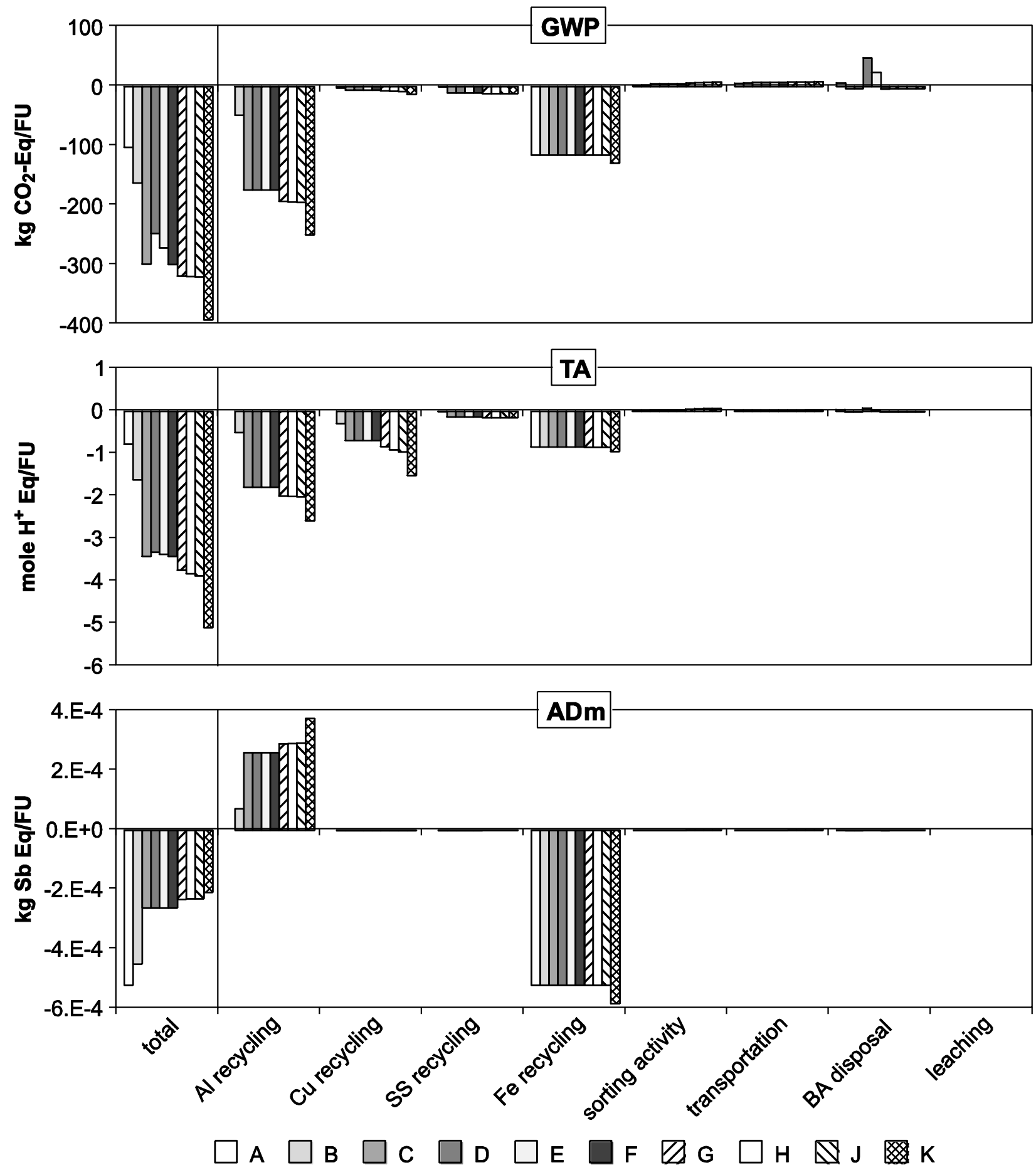

Figure 2 - LCA results of the three non-toxic impact categories global warming potential (GWP), acidification (AT) and depletion of abiotic mineral resources (ADm). Potential impacts are shown as total net characterised impact (on the left of each charts "total") and per individual group of system activities.

In general, even when reaching the GWP breakeven point for sole aluminium recycling activities, the total net GWP of the system was consistently negative because of the major benefits obtained by recovering copper, SS and Fe metals. However, substitution rates are also relevant for other metals such as Fe scrap, where the accumulation of alloying elements in the recycling chain leads 
to downcycling conditions. By setting a value for the substitution of Al scrap in scenario $\mathrm{C}$, and by varying substitution rates for SS $(\alpha)$ and Fe $\operatorname{scrap}(\gamma)$ between 0 and 1 , it was possible to estimate the values of the substitution parameters $(\alpha, \beta$, and $\gamma)$ for which the breakeven point for the entire system is reached (see Figure 3, upper charts): for a value of $\beta$ of 0.05 the breakeven point for GWP (i.e. GWP $=0$ ) was reached for values of $\gamma$ between 0.14 and 0.28 , irrespective of $\alpha$ value, no breakeven point was reached for $\beta=1$ and the maximum value of $\beta$ for having GWP=0 or positive was 0.27 . Thus, beyond a substitution rate of 0.27 recycling of Al scrap is expected to be beneficial regardless of the substitution rates for Fe and SS scrap.

In the last sensitivity analysis, by varying $\beta$ and $\gamma$, and the impact of sorting activities (i.e. by multiplying the impacts of these activities by a factor $>1$ ), conditions resulting in $G W P=0$ were defined for scenario $C$ and $K$ by a plane of points (see Figure 3 ). In scenario $C$, with the current energy demand for metal sorting, the breakeven point is found for a combination of parameter values of $\beta$ and $\gamma$ below 0.17 and 0.21 , respectively, and while assuming the maximum quality of metal scrap ( $\beta$ and $\gamma$ equal to 1 ), the impact of metal sorting could be increased by 70 times the current value before the breakeven point is reached. In scenario $K$, a breakeven point was not found, due to the increased recovery of HNFe metals. In order to reach the condition GWP=0 in scenario $\mathrm{K}$, the impact related to the sorting activities should be at least 50 times higher than the one assumed in the baseline, especially considering the lowest quality of recovered scrap metal (i.e. a substitution ration equal to 0 ). By varying the marginal technology for primary aluminium production from $100 \%$ coal-based electricity production in China to $100 \%$ natural gas-based in the Middle East, no breakeven point was reached in scenario $\mathrm{K}$, while this might occur in scenario $\mathrm{C}$ for an aluminium substitution rate below 0.29 .

\subsubsection{Potential impacts on acidification (TA) and the depletion of abiotic mineral resources (ADm)}

Potential impacts on acidification (TA) from the scenarios were overall negative and increasingly beneficial as scrap metal recovery increased (Figure 2). Potential impacts were mainly caused by emissions into the air of $\mathrm{SO}_{2}$ from the combustion of fossil fuels for electricity provision and direct emissions from the metal smelters. Concerning ADm, net impacts of the system were negative (Figure 2), with benefits decreasing in line with the increasing recovery of Al scrap. In particular, Al scrap recycling activities resulted in increased burdens, illustrating that increasing Al scrap recycling is associated with increased mineral resource consumption (mainly alloying elements). Avoiding primary aluminium production led to ADm savings of the order $-10^{-8} \mathrm{~kg} \mathrm{Sb}$-Eq per FU because of avoiding the exploitation of uranium (mainly related to energy provision processes), aluminium and iron, while secondary aluminium production resulted in burdens of the order $+10^{-4}$ $\mathrm{kg} \mathrm{Sb-Eq} \mathrm{per} \mathrm{FU,} \mathrm{mostly} \mathrm{caused} \mathrm{by} \mathrm{using} \mathrm{Zn}$ being used as an alloying element in the process. The process used for modelling secondary aluminium production was representative of a generic refiner in Europe treating old Al scrap and thus did not reflect the specificity of Al scrap from MSWI BA or secondary cast alloy production. Indeed, the addition of alloying elements to molten aluminium for secondary cast aluminium alloy production depends strictly on the chemical composition of the input scrap and on the desired final product. Refineries use a mixture of $\mathrm{Al}$ scrap types of relatively well-defined chemical compositions as inputs into the furnace, in order to obtain molten aluminium as close as possible to the final product composition, thus minimising the need to add primary aluminium as a sweetener (to dilute excess accumulated alloying elements) or alloying elements. Si is generally always added, while other metals (e.g. $\mathrm{Cu}, \mathrm{Mg}, \mathrm{Mn}$, $\mathrm{Zn}$ ) are more sensitive to scrap input quality and the selected final product. Within the list of 
alloying elements reported in the EN 1676:1996 standard, Si has the lowest characterisation factor (CF) for ADm followed by $\mathrm{Al}, \mathrm{Mg}$, $\mathrm{Ti}$ and Fe (i.e. CFs below $10^{-7} \mathrm{~kg} \mathrm{Sb}-\mathrm{Eq} / \mathrm{kg}$ ), while $\mathrm{Sn}, \mathrm{Pb}, \mathrm{Cu}, \mathrm{Zn}$, $\mathrm{Ni}, \mathrm{Cr}$ and $\mathrm{Mn}$, have CFs between $10^{-2}$ and $10^{-6} \mathrm{~kg} \mathrm{Sb}-\mathrm{Eq} / \mathrm{kg}$. Thus, based on the significant differences between CFs and the high case specificity of the actual exploitation of individual alloying elements, the ADm results provide important insights into the resource aspects of metal recycling, because they relate to the quality of the scrap and the secondary production phase which marginally substitutes the primary metal. The need to dilute the aluminium melt with primary aluminium, and the loss or accumulation of alloying elements, clearly indicates downcycling - and hence quality and functionality losses of aluminium scrap in the post-consumer and recycling phases.
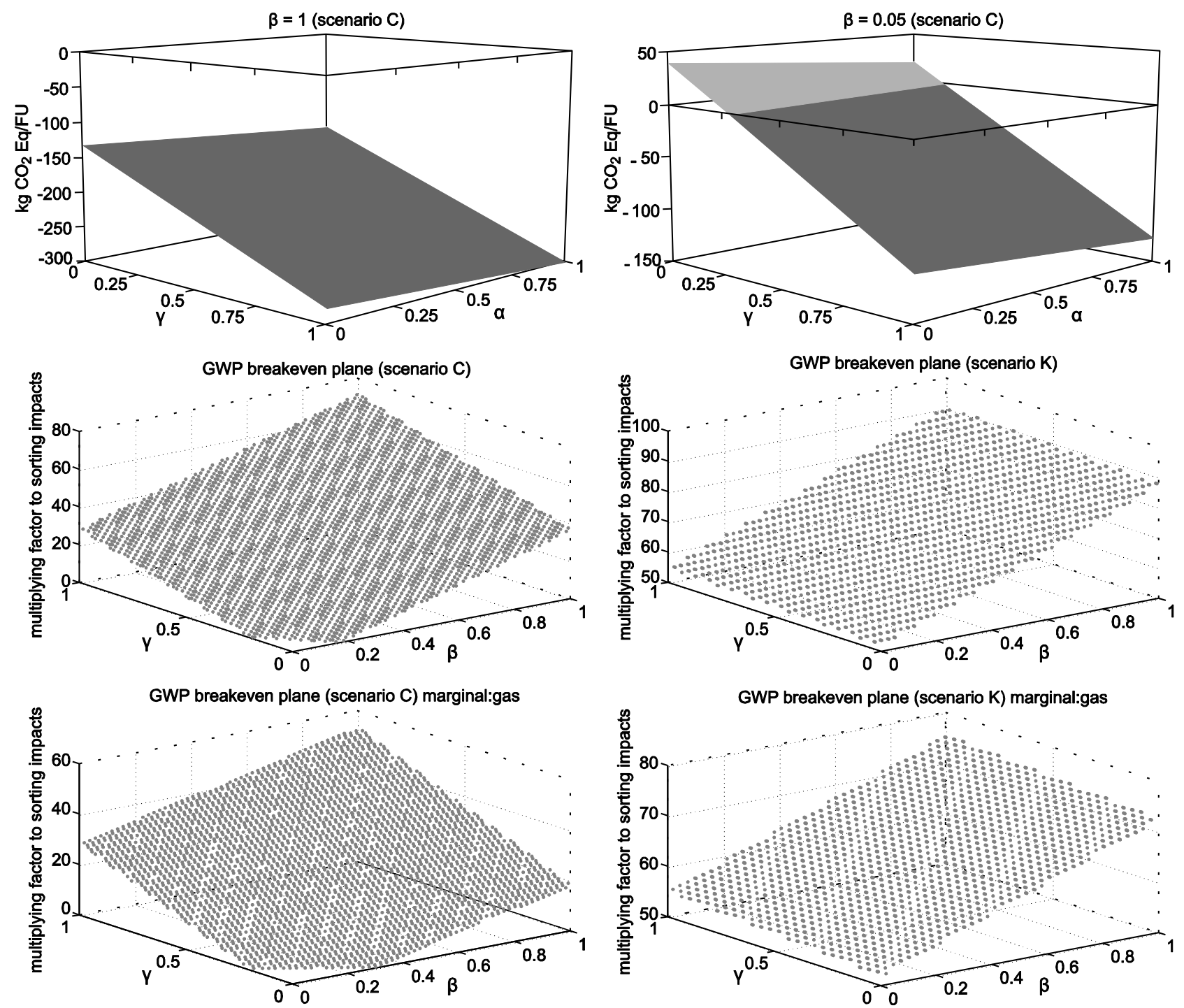

Figure 3 - Change of substitution ratios for metal recycling: effect on GWP. a) Net GWP for scenario C given a fixed aluminium substitution rate value $(\beta)$ and varying substitution rates for SS $(\alpha)$ and Fe scrap ( $(v)$; b) plane of breakeven points obtained by varying $\beta, \gamma$ and the impact due to sorting and upgrading activities of the scrap metals from MSWI BA for scenarios $C$ and $K$. The points represent values of GWP between -0.1 and 0.1 with varying $\beta, v ; c)$ same as b) but the Middle East primary production of aluminium is used as marginal technology (i.e. with electricity production based on $100 \%$ natural gas). 
Overall, non-toxic results showed that the benefits of metal recycling can be compromised by the quality of the recycled scrap metals. The practice of differentiating Al scrap by grain size possibly leads to higher benefits, as fine fractions with higher Al content could be potentially upcycled and sold to re-melters instead of refiners. However, the presence of metals from various origins in the post-incineration scrap limits the possibility to optimise alloying content for a specific secondary aluminium alloy. Moreover, the benefits of recovering such low-quality Al scrap may decrease in the near future. In fact, as reported by several studies, the availability of old Al scrap might exceed the demand for the relevant cast aluminium alloys over a near-to mid-term time horizon. As an example, a recent study by Modaresi and Müller (2012) estimated that a scrap surplus may even start to build up around 2018. Thus, increasing the recovery of mixed low-quality scrap might lead to the long-term accumulation of material that has no application in the market.

\subsection{Toxic potential impacts}

\subsubsection{Metal recycling}

Figure 4 reports the results for the toxic categories. For all scenarios, potential toxic impacts were positive for the three assessed impact categories, with the only exception being scenario $\mathrm{K}$ with a negative impact on HTnc and ET due to the significant recovery of NFe metals (Al, Cu). Fe scrap recycling showed the greatest contribution among all three categories: the results were positive for all scenarios and impact categories, meaning that the secondary production of iron contributes more impacts than primary production from a toxic perspective. However, this result was related to the way secondary and primary steel production was inventoried in the selected Ecoinvent process. In fact, emissions contributing the most were $\mathrm{Cr}(\mathrm{VI})$ into water (for HTc and ET), from the "disposal, slag, unalloyed electr. steel, $0 \%$ water, to residual material landfill/ $\mathrm{CH}^{\prime}$ process, and $\mathrm{Hg}$ into the air (HTnc), as a direct emission from the steel plant. The $\mathrm{Cr}(\mathrm{VI})$ emissions included in this inventory were large compared to those occurring in the leaching experiment results (e.g. Piatak et al., 2014) - a discrepancy which appears to play a critical role and might explain the results. However, because of a lack of direct data and information about the actual utilisation/disposal of Fe slag, the Ecoinvent process inventory was not modified.

Concerning aluminium recycling, savings in relation to HTC and ET were mainly due to avoiding the disposal of red mud from bauxite mining, while burdens on HTnc were related to the production of $\mathrm{Zn}$, to be used as an alloying element. However, as in the case of slag disposal from iron scrap recycling, and based on the discussion about the utilisation of alloying elements in secondary aluminium production (cf. section 3.1.3), the toxicity results for metallurgical activities may be subject to a great deal of uncertainty. In addition to the uncertainty related to the inventory, the results in the toxicity-related impact categories are subjected to a high level of uncertainty due to the high inherent uncertainty associated with the impact characterisation of potentially toxic emissions. Particularly, the characterisation of emissions of inorganic pollutants represents a great deal of uncertainty within the selected characterisation method (i.e. USEtox) and should only be used with caution (Rosenbaum et al. 2008). 

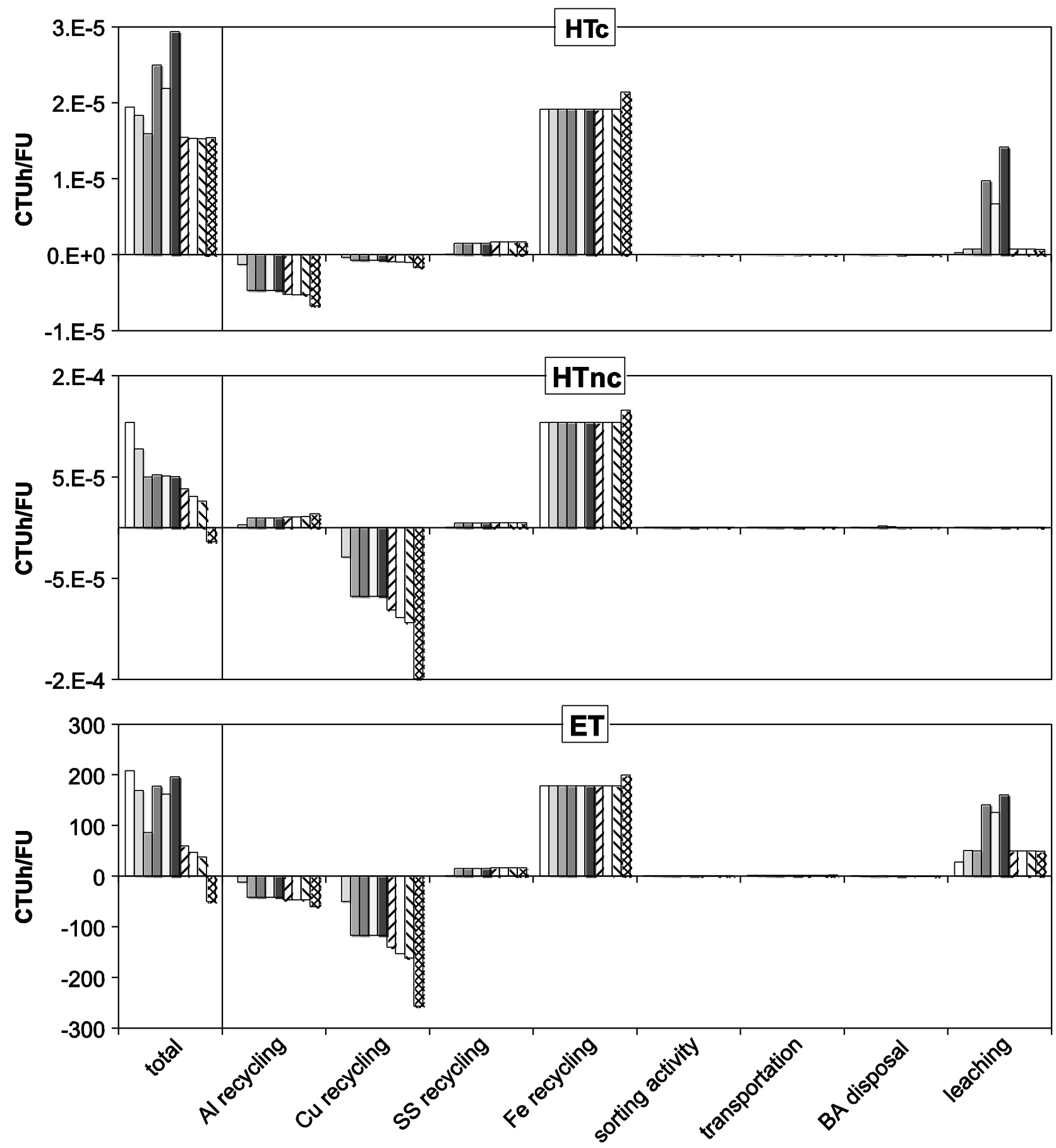
A
B
C $\square$ D
$\square \mathrm{E}$
$\mathrm{F} \square \mathrm{G} \square \mathrm{H} \otimes \mathrm{J}$

Figure 4 - LCA results for the toxic impact categories. The impacts are shown as total net impact (on the left of each chart's "total") and per individual group of activities in the system. 


\subsubsection{MSWI BA disposal and reuse}

The release of potentially toxic metals as a result of utilising or disposing of MSWI BA represents a significant contribution to potential impacts on the HTc and ET categories (Figure 4), with emissions during the utilisation of MSWI BA as aggregate in concrete showing the greatest contribution. In Figure 5, toxic impacts caused by the leaching of metals from disposing of or utilising MSWI BA are reported in detail. Potential impacts generated in scenarios A (landfill) and C (road) were comparable (i.e. the same order of magnitude); however, across the 100-year time horizon used in this instance, the impact of using BA as aggregate in road was slightly greater than the landfill case, thereby reflecting the lower L/S ratio reached in the landfill scenario. This result was in agreement with previous studies by Birgisdóttir et al. (2007) and Toller et al. (2009). Furthermore, in scenarios $\mathrm{A}$ and $\mathrm{C}, \mathrm{Cu}$ made the greatest contribution to the impact on $\mathrm{ET}$, as also reported by other authors (e.g. Toller et al., 2009). Cr dominated HTc impacts, while As and Zn (and Mo, to a lesser extent) were most important for the HTnc impact category. Impacts from scenarios D, E and $F(100 \%$ substitution of natural aggregate with BA in concrete) were more than one order of magnitude higher than impacts from the road scenario for HTc, and they were approximately three times higher for ET, while for HTnc the results were comparable to the road case, except for scenario $E$ (concrete type 2 ) which resulted in negative impacts. The impact on HTnc was mainly determined by As; however, As was released in low concentrations (often below the analytical limit of detection) during the leaching tests applied to MSWI BA, gravel and concrete specimens (with and without $B A$ ), and so the net resulting impact was pretty much zero.

The high impact on HTc for scenarios D, E and F was caused by increased $\mathrm{Cr}$ release after carbonating concrete specimens which were then utilised in a road sub-base. The increased release of $\mathrm{Cr}$ and other elements after ageing was observed by other authors (e.g. Baciocchi et al., 2010 and Chimenos et al., 2003). Leachate from the concrete specimens with BA did not comply with release limits set by the Danish statutory order N. 1662 (2010), because of the measured release of $\mathrm{Cr}$ and Se. However, leachate from the same crushed concrete, before laboratory ageing, was not compliant for reuse because of the excessive release of $\mathrm{Pb}$. Significant leaching of $\mathrm{Cr}$ was measured from the reference concrete specimens as well, in line with typical literature values (Butera et al., 2014). However, $\mathrm{Cr}$ released from the specimens containing BA was at least three times higher than what would have been found for the aged reference concrete and more than five times greater than what is released from MSWI BA (cf. Fig. B.1. in Appendix B for an overview of the release from the different samples). The higher release of $\mathrm{Cr}$ compared with the release from MSWI BA could not be explained by the fact that only the fine fraction of BA was used as aggregate in the concrete. Although leaching test results on individual BA fractions (see Fig. B.2. in Appendix) showed a higher release of $\mathrm{Cr}$ from BA fractions below $8 \mathrm{~mm}$ compared with the coarser fractions, the difference was not significant compared with releases from the entire BA sample. On the other hand, one possible explanation may be related to the level of carbonation in relation to the crushed concrete specimens after laboratory ageing and BA collected at the facility. The MSWI BA analysed in this study was collected after a mild ageing process at the facility, and it subsequently presented a $\mathrm{pH}$ of around 11.5, while the concrete specimens after laboratory ageing had $\mathrm{pH}$ values between 9.6 and 11 . Relatively to $\mathrm{ET}$, the impact from utilising concrete specimens containing MSWI BA in outdoor pavements was comparable to the impact seen after 50 years in a road following the demolition of the concrete specimens. $\mathrm{Cr}, \mathrm{Sb}, \mathrm{Cu}, \mathrm{V}$ and $\mathrm{Zn}$ were the main contributors to the impact during the first 50 years in the outdoor pavement, while $\mathrm{Cr}$, and to a lesser extent $\mathrm{Cu}$ and $\mathrm{Sb}$, was important in the recycling phase of crushed concrete in the 
road. However, a service life of 50 years for outdoor concrete tiles is quite unrealistic, as it is more likely to be between 5 and 20 years, meaning that the impact of the recycling phase of the crushed concrete is dominant in the life cycle of concrete tiles.
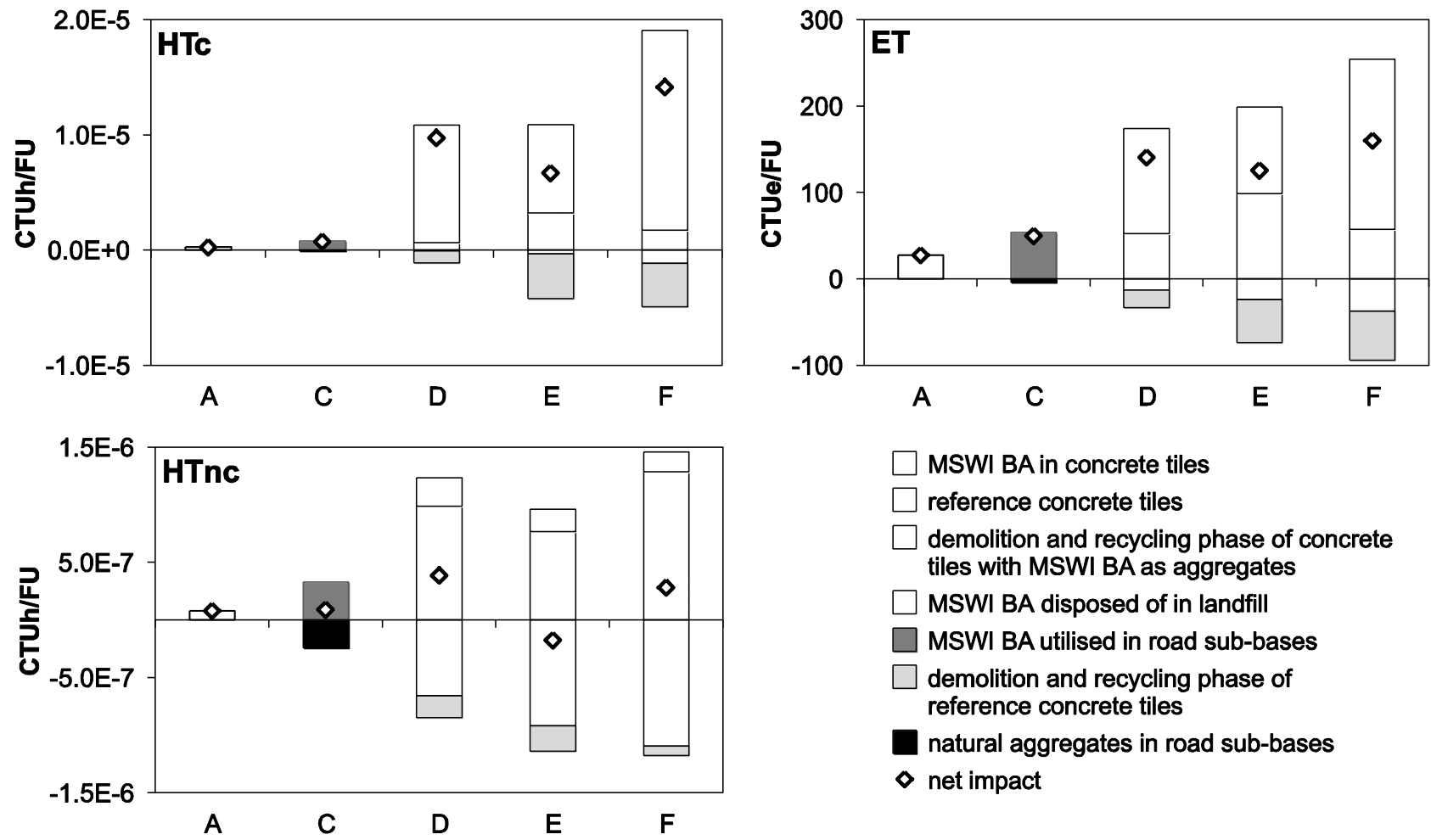

MSWI BA in concrete tiles $\square$ reference concrete tiles

$\square$ demolition and recycling phase of concrete tiles with MSWI BA as aggregates MSWI BA disposed of in landfill MSWI BA utilised in road sub-bases demolition and recycling phase of reference concrete tiles

natural aggregates in road sub-bases

$\diamond$ net impact

Figure 5 - Potential toxic impacts of MSWI BA disposal or utilisation scenarios due to the leaching of metals into the environment. Positive values represent loads, negative values represent avoided emissions and diamonds indicate net values. [A: landfill disposal; C: aggregate in road sub-base; D: aggregate in concrete type 1; E: aggregate in concrete type 2; F: aggregate in concrete type 3].

\section{Conclusions}

MSWI BA metal recovery and material utilisation were addressed from an environmental perspective. An existing MSWI BA recovery system and its alternative configurations were analysed using the LCA methodology. All relevant activities were included in the system boundaries, namely metal sorting, upgrading, transportation and recycling, transport and the utilisation or disposal of MSWI BA. Results for the non-toxic impact categories showed savings associated with metal recycling activities; in particular, benefits to the GWP category increased proportionally in line with increasing metal recovery. Results for the GWP category were sensitive to the choice of marginal technology assumed to respond to the increase in metal supply from MSWI BA scrap recovery, and to the substitution rate between secondary and primary metals. With currently available metal recovery efficiencies, and by applying substitution ratios below 0.17 and 0.21 , respectively, for Al and Fe scrap, a breakeven point for the GWP category can be achieved. Moreover, by defining the aluminium substitution rate with a price ratio between $\mathrm{Al}$ scrap or secondary aluminium and primary aluminium, possible substitution values reach between 0.35 and 0.05 . Potential impacts on toxic categories were positive, owing to the contributions of metallurgical activities, including the disposal of associated residues, and the leaching of metal 
from disposing of and utilising MSWI BA. Leaching test data were applied to estimate the release of toxic metals into the environment from MSWI BA. Landfill disposal or the utilisation of the material as aggregate in roads were both preferable over the use of MSWI BA as aggregate in concrete, due to metal leaching during the recycling phase of the demolished concrete specimens.

\section{Acknowledgements}

This research was funded partially by AFATEK Ltd. and by the Danish Research Council as a part of the IRMAR (Integrated Resource Management \& Recovery) initiative. AFATEK Ltd., RGS90 Ltd. and Scanmetals Ltd. are acknowledged for providing the data and information necessary for performing the study. Martin Kaasgaard and Claus Pade, from DTI, Teknologisk Institut, Byggeri og anlæg, Beton, are acknowledged for providing concrete specimens and information about concrete production using MSWI BA. The Authors would also like to thank Sinh Hy Nguyen and Susanne Kruse for their assistance in the laboratory work and Maria Antonia Sunyer Pinya for helping preparing some of the figures.

Supporting information

Supplementary data associated with this article can be found in the online version at XXXX. 


\section{References}

ACEA, 2010. European Automobile Manufacturers Association. Passenger cars world statistics.

AFATEK, 2009. Bottom ash. Content of metals. Internal report in Danish (Danish title: Råslagge. Inhold af jern og metal).

Allegrini, E., Maresca, A., Olsson, M.E., Holtze, M.S., Boldrin, A., Astrup, T.F., 2014. Quantification of the Resource Recovery Potential of Municipal Solid Waste Incineration Bottom Ashes. Waste Manage. 34(9), 1627-1636.

ASTM B479, 2006. Standard Specification for Annealed Aluminum and Aluminum-Alloy Foil for Flexible Barrier, Food Contact, and Other Applications. DOI: 10.1520/B0479-06

Astrup, F.T., Pedersen, A.J., Hyks, J., Frandsen, J.F., 2010. Residues from waste incineration. PSO5784.

Astrup, F.T., Mosbæk, H., Christensen, T.H., 2006. Assessment of long-term leaching from waste incineration air-pollution-control residues. Waste Manage. 26, 803-814.

Baciocchi, R., Costa, G., Lategano, E., Marini, C., Polettini, A., Pomi, R., Postorino, P., Rocca, S., 2010. Accelerated carbonation of different size fractions of bottom ash from RDF incineration. Waste Manage. 30, 1310-1317.

Barberio, G., Buttol, P., Masoni, P., Scalbi, S., Andreola, F., Barbieri, L., Lancellotti, I., 2010. Use of Incinerator Bottom Ash for Frit Production. J. Ind. Ecol. 14, 200-216.

Biganzoli, L., Gorla, L., Nessi, S., Grosso, M., 2012. Volatilisation and oxidation of aluminium scraps fed into incineration furnaces. Waste Manage. 32, 2266-2272.

Biganzoli, L., Ilyas, A., Van Praagh, M., Persson, K.M., Grosso, M., 2013. Aluminium recovery vs. hydrogen production as resource recovery options for fine MSWI bottom ash fraction. Waste Manage. 33(5), 1174-1181.

Biganzoli, L., Grosso, M., 2013. Aluminium recovery from waste incineration bottom ash, and its oxidation level. Waste Manage. Res. 31, 954-959.

Birgisdóttir, H., 2005. Life Cycle Assessment model for road construction and use of residues from waste incineration. PhD Thesis. Institute of Environment \& Resources, Technical University of Denmark, Lyngby, Denmark.

Birgisdóttir, H., Bhander, G., Hauschild, M.Z., Christensen, T.H., 2007. Life cycle assessment of disposal of residues from municipal solid waste incineration: Recycling of bottom ash in road construction or landfilling in Denmark evaluated in the ROAD-RES model. Waste Manage. 27, S75-S84.

Boesch, M.E., Vadenbo, C., Saner, D., Huter, C., Hellweg, S., 2014. An LCA model for waste incineration enhanced with new technologies for metal recovery and application to the case of Switzerland. Waste Manage. 34(2), 378-389.

Butera, S., Christensen, T.H., Astrup, T.F., 2014. Composition and leaching of construction and demolition waste: Inorganic elements and organic compounds. J. Hazard. Mater. 276, 302-311.

Chimenos, J.M., Fernández, A.I., Miralles, L., Segarra, M., Espiell, F., 2003. Short-term natural weathering of MSWI bottom ash as a function of particle size. Waste Manage. 23, 887-895. 
Crillesen, K., Skaarup, J., 2006. Management of Bottom Ash from WTE Plants-An overview of management options and treatment methods. Report of the International Solid Waste Association (ISWA).

De Vries, W., Rem, P.C., De Keizer, M., 2012. Value creation out of MSWI bottom ash. In the proceedings of WASCON 2012 - towards effective, durable and sustainable production and use of alternative materials in construction. 8th International conference on sustainable management of waste and recycled materials in construction, Gothenburg, Sweden.

Doka, G., Hischier, R., 2005. Waste treatment and assessment of long-term emissions. Int. J. LCA $10,77-84$.

EAA, 2013a. Aluminium recycling in LCA.

EAA, 2013b. Environmental profile report for the European aluminium industry.

EC-JRC, 2010. ILCD Handbook. General guide for Life Cycle Assessment-Detailed guidance.

EN 12457-1, 2002. Characterization of waste - Leaching - Compliance test for leaching of granular waste materials and sludges - Part 1: One stage batch test at a liquid to solid ratio of $2 \mathrm{l} / \mathrm{kg}$ for materials with high solid content and with particle size below $4 \mathrm{~mm}$.

EN 1676, 1996. Aluminium and aluminium alloys. Alloyed ingots for re-melting. Specifications.

Eurostat, 2011. Generation and treatment of waste in Europe 2008. Report 44/2011.

N. 1662:2010. BEK nr. 1662 af 21/12/2010. Danish Statutory Order on the use of residues and soil for construction and the use of sorted, uncontaminated construction and demolition waste. In Danish (Danish title: Bekendtgørelse om anvendelse af restprodukter og jord til bygge og anlægsarbejder og om anvendelse af sorteret, uforurenet bygge- og anlægsaffald).

NEN 7371, 2004, the determination of the availability of inorganic components for leaching 'the maximum availability leaching test'. Translation of the Dutch waste characterisation standards NEN 7341 (1995) and NEN 7371 (2004).

NEN 7375, 2005. Leaching characteristics of moulded or monolithic building and waste materials. Determination of leaching of inorganic components with the diffusion test.

Fruergaard, T., Astrup, F.T., Ekvall, T., 2009. Energy use and recovery in waste management and implications for accounting of greenhouse gases and global warming contributions. Waste Manage. Res. 27, 724-737.

Fruergaard, T., 2010. Environmental Sustainable Utilisation of Waste Resources for Energy Production; Environmental Sustainable Utilisation of Waste Resources for Energy Production. Department of Environmental Engineering, Technical University of Denmark (DTU).

Georgeson, R., 2006. Environmental Benefits of Recycling, An international review of life cycle comparisons for key materials in the UK recycling sector. Waste \& Resources Action Programme (WRAP), ISBN, 1-84405.

Grosso, M., Biganzoli, L., Rigamonti, L., 2011. A quantitative estimate of potential aluminium recovery from incineration bottom ashes. Resour. Conserv. Recycling 55, 1178-1184. 
Hauschild, M.Z., Goedkoop, M., Guinée, J., Heijungs, R., Huijbregts, M., Jolliet, O., Margni, M., De Schryver, A., Humbert, S., Laurent, A., Sala, S., Pant, R., 2013. Identifying best existing practice for characterization modeling in life cycle impact assessment. Int. J. LCA, 18(3), 683-697.

Heinrichs, S., Wens, B., Feil, A., Pretz, T., 2012. Recovery of nf-metals from bottom ash's fine fraction - state-of-the-art in Germany. In the proceedings of the Fourth International Symposium on Energy from Biomass and Waste Venice 2012. Venice, Italy.

Hu, Y., Bakker, M.C.M., de Heij, P.G., 2011a. Recovery and distribution of incinerated aluminium packaging waste. Waste Manage. 31, 2422-2430.

Hu, Y., Bakker, M., Brem, G., Chen, G., 2011b. Controlled combustion tests and bottom ash analysis using household waste with varying composition. Waste Manage. 31, 259-266.

Hu, Y., Rem, P., 2009. Aluminium alloys in municipal solid waste incineration bottom ash. Waste Manage. Res. 27, 251-7.

IAI, 2013. Global life cycle inventory data for the primary aluminium industry.

ICCT, 2013. The international council on clean transportation. European vehicle market statistics. Pocketbook 2013.

ICSG, 2013. The world copper fact book 2013.

IEA, 2008. International energy agency, World energy outlook, 2008.

ISSF, 2013. Stainless steel in figures.

Koffler, C., Florin, J., 2013. Tackling the downcycling issue - A revised approach to value-corrected substitution in life cycle assessment of aluminium (VCS 2.0). Sustainability (Switzerland) 5, 4546-4560.

Kosson, D.S., Van der Sloot, H.A., Eighmy, T.T., 1996. An approach for estimation of contaminant release during utilisation and disposal of municipal waste combustion residues. J. Hazard. Mater. 47, 43-75.

Kuusiola, T., Wierink, M., Heiskanen, K., 2012. Comparison of collection schemes of municipal solid waste metallic fraction: The impacts on global warming potential for the case of the Helsinki metropolitan area, Finland. Sustainability. 4, 2586-2610.

Laner, D., 2009. The consideration of long-term emissions from landfills within life-cycle assessment. Waste Manage. Res. 27, 463-470.

Margallo, M., Aldaco, R., Irabien, Á, 2014. Environmental management of bottom ash from municipal solid waste incineration based on a life cycle assessment approach. Clean Technologies and Environmental Policy.

Meylan, G., Spoerri, A., 2014. Eco-efficiency assessment of options for metal recovery from incineration residues: A conceptual framework. Waste Manage. 34, 93-100.

Modaresi, R., Müller, D.B., 2012. The role of automobiles for the future of aluminum recycling. Environ. Sci. Technol. 46, 8587-8594. 
Morf, L.S., Di Lorenzo, F., Skutan, S., Böni, D., Haupt, M., Haag, O., Gloor, R., 2013. Precious metals and rare earth elements in municipal solid waste - Sources and fate in a Swiss incineration plant. Waste Manage. 33, 634-644.

Muchova, L., 2010. Wet physical separation of MSWI bottom ash. PhD Thesis. Technical University of Delft, Delft, The Netherlands.

Muchová, L., Rem, P.C., 2006. Metal content and recovery of MSWI bottom ash in Amsterdam. WIT Trans. Eco. Environ. 92, 211-216.

Nakajima, K., Takeda, O., Miki, T., Matsubae, K., Nakamura, S., Nagasaka, T., 2010. Thermodynamic analysis of contamination by alloying elements in aluminum recycling. Environ. Sci. Technol. 44, 5594-5600.

Nakajima, K., Takeda, O., Miki, T., Matsubae, K., Nagasaka, T., 2011. Thermodynamic Analysis for the Controllability of Elements in the Recycling Process of Metals. Environ. Sci. Technol. 45, 4929-4936.

OICA, 2014. Organization of Motor Vehicle Manufacturers. Production statistics.

Pecqueur, G., Crignon, C., Quénée, B., 2001. Behaviour of cement-treated MSWI bottom ash. Waste Manage. 21, 229-233.

Piatak, N.M., Parsons, M.B., Seal II, R.R., 2014. Characteristics and environmental aspects of slag: A review. Appl. Geochem.

Posch, M., Seppälä, J., Hettelingh, J., Johansson, M., Margni, M., Jolliet, O., 2008. The role of atmospheric dispersion models and ecosystem sensitivity in the determination of characterisation factors for acidifying and eutrophying emissions in LCIA. Int. J. LCA 13, 477-486.

prEN 14405, 2014. Characterisation of waste - Leaching behaviour tests - Up-flow percolation test (under specified conditions).

Rosenbaum, R.K., Bachmann, T.M., Gold, L.S., Huijbregts, M.A.J., Jolliet, O., Juraske, R., Koehler, A., Larsen, H.F., MacLeod, M., Margni, M., McKone, T.E., Payet, J., Schuhmacher, M., Van De Meent, D., Hauschild, M.Z., 2008. USEtox - The UNEP-SETAC toxicity model: Recommended characterisation factors for human toxicity and freshwater ecotoxicity in life cycle impact assessment. Int. J. LCA 13, 532-546.

Schlesinger, M.E., King, M.J., Sole, K.C., Davenport, W.G., 2011. Extractive metallurgy of copper. Elsevier.

Schmidt, J.H., Thrane, M., 2009. Life cycle assessment of aluminium production in new Alcoa smelter in Greenland. LCA report.

Seppälä, J., Posch, M., Johansson, M., Hettelingh, J., 2006. Country-dependent Characterisation Factors for Acidification and Terrestrial Eutrophication Based on Accumulated Exceedance as an Impact Category Indicator (14 pp). Int. J. LCA 11, 403-416.

Sevigné-Itoiz, E., Gasol, C.M., Rieradevall, J., Gabarrell, X., 2014. Environmental consequences of recycling aluminum old scrap in a global market. Resour. Conserv. Recycling. 89, 94-103.

Toller, S., Kärrman E., Gustafsson, J.P., Magnusson, Y., 2009. Environmental assessment of incinerator residue utilisation. Waste Manage. 29, 2071-2077. 
Van Oers, L., De Koning, A., Guinée, J.B., Huppes, G., 2002. Abiotic resource depletion in LCA. Road and Hydraulic Engineering Institute, Ministry of Transport and Water, Amsterdam.

Van der Wegen G., Hofstra U., Speerstra J., 2013. Upgraded MSWI Bottom Ash as Aggregate in Concrete. Waste Biomass. Valor. 4, 737-743.

Weidema, B.P., Frees, N., Nielsen, A., 1999. Marginal production technologies for life cycle inventories. Int. J. LCA 4, 48-56.

World steel association, 2013. World steel in figures.

ZAR, 2014. Foundation development centre for sustainable management of recyclable waste and resources. Waste and resource management. Innovative, Practical, Economic. Annual Report 2013. 